\title{
STABILITY OF LYAPUNOV EXPONENTS, WEAK INTEGRAL SEPARATION AND NONUNIFORM DICHOTOMY SPECTRUM
}

\author{
Hailong $\mathrm{Zhu}^{1}$ and Zhaoxiang $\mathrm{LI}^{2}$ \\ ${ }^{1}$ Anhui University of Finance and Economics \\ ${ }^{2}$ Shanghai Normal University - Xuhui Campus
}

September 25, 2021

\begin{abstract}
In this paper, a necessary and sufficient condition for the stability of Lyapunov exponents of linear differential system is proved in the sense that the equations satisfy the weaker form of integral separation instead of its classical one. Furthermore, the existence of full nonuniform exponential dichotomy spectrum under the condition of weak integral separateness is also presented.
\end{abstract}

\section{Hosted file}

zhu-final.pdf available at https://authorea.com/users/437675/articles/539149-stability-oflyapunov-exponents-weak-integral-separation-and-nonuniform-dichotomy-spectrum 